\title{
Autism and the Academic Library: A Study of Online Communication
}

\section{Amelia Anderson}

\begin{abstract}
Increased prevalence of autism spectrum disorder (ASD) diagnoses within the general population is reflected in the growing number of college and university students with ASD. This exploratory study used an unobtrusive qualitative content analysis design to explore the experiences of students with ASD in academic libraries. It seeks to understand their questions and concerns, as well as their experiences in using the library and library resources. Using the social model of disability studies, this study allows for voices of students with ASD to be presented in their own words, not through the perceptions of parents, caregivers, faculty, or staff.
\end{abstract}

\section{Introduction}

Autism spectrum disorder (ASD) continues to increase in prevalence for multiple reasons, including improved diagnostic and reporting procedures, a rise in public awareness of the disorder, and an expanded definition of ASD. It is also likely that the number of individuals with ASD is simply increasing. As the prevalence increases, individuals with ASD are entering institutes of higher education (IHE) in increasing numbers. ${ }^{1}$ Though characteristics of ASD vary in every person, individuals on the autism spectrum typically face communicative and social challenges; they also tend to have fixed interests and display repetitive behaviors. ${ }^{2}$

Much of the previous study of individuals on the autism spectrum focuses on children with the disorder. In the library and information science (LIS) field, very few studies mention adolescents or adults with ASD. One librarian who also has ASD says that this is not specific to LIS studies; rather, it is reflective of writings and research as a whole. ${ }^{3}$ As she states, "this systematic focus on children renders Autistic adults invisible."

Many individuals with ASD use, appreciate, and even work and volunteer for libraries, ${ }^{5}$ and in one first-person narrative from 2002, an individual with ASD has described his school library as a "sanctuary." ${ }^{6}$ If the library truly is a "sanctuary" for students with ASD, better understanding and, thus, better services for these students could help support them as college students in general. There are numerous barriers for students with ASD in attending and graduating from college successfully. ${ }^{7}$ If the library can serve as a safe and welcoming place for these students, it will help contribute to their ultimate college success.

One way to ensure this success is to get input from members of the community involved, and community members of the website www.wrongplanet.net (Wrong Planet)

Amelia Anderson is an Assistant Professor at Old Dominion University; e-mail: ameliamaclay@gmail. com. (C2018 Amelia Anderson, Attribution-NonCommercial (http://creativecommons.org/licenses/by$n c / 4.0 /)$ CC BY-NC. 
are those who are considered in this study. These Wrong Planet members self-identify as having ASD, and, among other topics, members do discuss their experiences in libraries with one another. This study focuses on the information exchanged among members of this population as they describe their experiences with the academic library.

\section{Research Questions}

This study is guided by the following research question, along with related subquestions.

RQ1: How do individuals with ASD describe their experiences in the academic library in an online community of their peers?

- How do members of this population describe the library's physical environment?

- How do members of this population describe their interactions with library resources?

- How do members of this population describe their social and communication experiences at the library and with librarians?

\section{Literature Review}

While this study is among the first to investigate persons with ASD in academic libraries, some limited literature describes how individuals with ASD experience postsecondary education and libraries individually. This study fills a gap in the literature by addressing members of this population in the intersection of both environments.

\section{Autism and Higher Education}

Though symptoms manifest quite differently in every individual on the autism spectrum, there are also many common shared characteristics within this population. The American Psychiatric Association (APA) lists some of these common characteristics as communication deficits, dependence on routines, and showing sensitivity to change. ${ }^{8}$ Further, individuals on the autism spectrum might display difficulty making eye contact, lack of tone or correct pitch in speech patterns, difficulty in auditory, visual, or intellectual processing, high anxiety, challenges in interpreting senses of humor and figures of speech, and general difficulties with social interaction. ${ }^{9}$ Anxiety and exhaustion is heightened when these individuals constantly work to model their behavior to reflect that which is expected in typical communication, such as forcing eye contact or struggling to manage hand gestures, body language, or speech patterns. ${ }^{10}$

As the prevalence in ASD diagnoses increases, so does the prevalence of individuals with ASD entering into institutes of higher education. ${ }^{11}$ Though these students face many challenges, they also display many strengths in the higher education environment. ${ }^{12}$ The literature reflects a trend of increasing awareness and acceptance of students with ASD on college campuses. ${ }^{13}$

Many educational supports are in place to assist college students with disabilities including those with ASD. Legislation such as the Individuals with Disabilities Education Act (IDEA) and the Americans with Disabilities Act (ADA) has made the college experience more accessible to students with ASD. ${ }^{14}$ However, institutes of higher education are still learning how to best provide services for this population, as students with ASD differ from many other students with special needs. They require more social and emotional support than academic support, and characteristics of the disorder are often invisible, leading to challenges in offering targeted support. ${ }^{15}$

Though identifying students with ASD who may need targeted services can be complicated, supports from college and university offices of disability services are available, by law, to students who disclose their diagnoses. Examples of these services include note-takers, extra time for exams, and alternate locations for exams in a less 
distracting environment. ${ }^{16}$ However, they must disclose their ASD and request assistance for these targeted services.

In contrast, if a student feels uncomfortable sharing his or her diagnosis, even with the Office of Disability Services, he/she will not have access to said services. ${ }^{17}$ Some college students try to make it on their own without any supports or are uncomfortable revealing their disability status, so they fail to notify the disability office of their diagnosis or their potential need for support. ${ }^{18}$ Other college students are unable to receive targeted supports because they are undiagnosed, though displaying characteristics of and self-identifying as having ASD. ${ }^{19}$

Training and education is crucial for the campus community to better provide these services for students with ASD. ${ }^{20}$ The more a campus community is knowledgeable about ASD, the more likely they will be able to help students' success. ${ }^{21}$ As stated by Emily Lawrence, a librarian with ASD, "educating neurotypical individuals about Autistic people is an effective means to improving well-being for Autistics." ${ }^{22}$

There is little research about the college experiences of students with ASD themselves, instead focusing on the experiences or impressions of parents, teachers, or administration. ${ }^{23}$ Dawn Prince-Hughes, an academic as well as a person with autism, suggests that such firsthand accounts of individuals with ASD are typically not sought or published, as readers not on the spectrum, also known as neurotypicals, are not familiar with following the train of thought of those with ASD. ${ }^{24}$ She notes that, traditionally, accounts from individuals with ASD have been heavily edited.

\section{Autism and Libraries}

Sensory overload, which could include overstimulation from noise, visuals, or other experiences, can occur for individuals with ASD when the environment poses many distractions. ${ }^{25}$ Personal narratives suggest individuals with ASD appreciate and find comfort in the library environment. ${ }^{26}$ Libraries seem to be an ideal environment for members of the ASD population, as they typically have logical layouts, clear signage, organized collections, and access to quiet spaces. ${ }^{27}$ College students with ASD often choose the library as a place to escape sensory distractions and to study in a quiet environment, ${ }^{28}$ and there are several resources indicating that librarians understand the need to reach out to this community. ${ }^{29}$

\section{Conceptual Framework}

This study operates using the social model of disability studies, which emphasizes disability as a social construct. This is in contrast to the medical model, which emphasizes disability as a problem that an individual needs to fix. Instead of seeking to treat college students with ASD or asking them to modify their behaviors, this study carries the view that, instead, one should view ASD "as a valid and even interesting difference from the neurological norm ${ }^{\prime \prime 30}$ or a difference, not a deficit. Creating inclusive environments is one approach that fits within this model, as is raising awareness and acceptance about the differences that those with ASD might display.

Studies concerned with individuals with ASD in the online environment find that many self-advocacy websites "challenge the medical model approach to defining AS as a pathology, instead re-positioning the condition as a valid and even interesting difference from the neurological norm." ${ }^{31}$ Though some parents, caregivers, and activists are concerned that the social model disregards the fact that individuals with ASD do have a legitimate diagnosis and individualized needs, most of the ASD advocacy literature supports the social model as a "guiding consideration that enhances our appreciation of the role society plays in the definition and actuality of disability" instead of a more extreme, polarizing view that disregards the medical model in entirety. ${ }^{32}$ 
The social model is often used as a framework in self-advocacy works; this study uses the model to provide guidance in analysis and discussion of the findings. In doing so, the study frames findings in an approach based on factors that can be controlled by librarians and higher education administrators - not in making suggestions for the students with ASD to change or modify their behavior, but in making environmental modifications to make for a more inclusive environment.

Within the social model of disability studies, it is common to use disability-first, as opposed to person-first, language. That is, many individuals with ASD prefer to refer to themselves as autistic. ${ }^{33}$ In this sense, this study detours from the traditional sense of the social model of disability studies and uses person-first language, as is often the preferred language of researchers. This is a deliberate choice due to considerations within the current body of knowledge and in adhering to current standards in the literature, but it is done with the understanding that there is no one clear, correct approach.

\section{Methods}

This study uses qualitative content analysis to collect and analyze firsthand accounts from college students with ASD as they discuss academic libraries. Content analysis is often used as a form of quantitative research, though this study instead uses qualitative methods to collect and analyze data. Instead of establishing categories and counting codes, "In qualitative research, small numbers of texts and documents may be analysed for a very different purpose. The aim is to understand the participants' categories." ${ }^{\prime 34}$ This study seeks to understand experiences as described by the individuals themselves; thus, a qualitative approach to content analysis is appropriate. Additionally, qualitative content analysis has already successfully been used to study online communications, as evidenced by the literature. ${ }^{35}$

Face-to-face communication can be a challenge for those on the autism spectrum, as some might have difficulties with making eye contact, using excessive gesturing, and misunderstanding body language or social cues. However, difficulty with faceto-face communication is not reflective of holistic communicative abilities, or a lack of want or need to communicate, ${ }^{36}$ and Internet technologies might be a solution to facilitate communication for individuals on the spectrum. ${ }^{37}$ Frequently described in the literature, and used in this study for its robust membership, is Wrong Planet (www.wrongplanet.net), a website that hosts public discussion forums, blogs, and news for individuals with ASD. ${ }^{38}$ Since its founding in 2004, the site has grown to more than 80,000 registered members, most of whom describe themselves as having Asperger's syndrome, or high-functioning autism, ${ }^{39}$ and live primarily in the United States. ${ }^{40}$ Though functional labels such as "high-functioning" are controversial, this is a common term in the literature to describe individuals formerly diagnosed as having Asperger's syndrome.

The discussion board posts sampled were those that fit the keyword criteria within the Wrong Planet discussion board threads. The Wrong Planet site can be searched using an advanced Google search. Boolean searches used combinations of the following keywords:

"library; librarian; lib; AND college; university; uni; campus"

The sampling frame included posts from all years available on Wrong Planet, which was established in 2004. A total of 170 discussion threads contained information that met the sampling criteria. Each thread was read in entirety to determine relevance to this study. From this examination, 72 of these discussion threads were determined to be irrelevant to the topic in entirety, leaving 98 discussion threads included for analysis. 


\section{Data Analysis}

Units of analysis were determined by message. That is, each post within a discussion thread was considered a unit of analysis. As described by one qualitative content analysis researcher, "by coding the whole message into one code, important information about the different themes within that message might be lost." ${ }^{\prime 1}$ To protect against loss of information, multiple coding was allowed within each unit or discussion post.

A codebook was created using emerging themes and the research questions. Open coding was used for units of analysis that did not fit within the codebook so that the data are represented in participants' own words. Data were coded using both inductive and deductive methods, in using the research questions as guiding factors. The study used an iterative process of coding and coding consistency checks, using one unpaid volunteer, a doctoral student interested in gaining research experience, for triangulating analysis (Patton, 2002). ${ }^{42}$

\section{Ethical Considerations}

Within Wrong Planet, there is a clear distinction between public and private content in that the site allows users to post to public boards or to private boards. Users can $\log$ in to access content visible just to them, and visitors to the site can view all of the public content without logging in. This study only used content that was made publicly available and viewable without logging in to the site. That being said, all user names were changed and pseudonyms are used in the findings and discussion to help protect users' identities, as has been done in previous content analyses with the ASD population. ${ }^{43}$ If there was any identifying information within the data, this was edited or removed to further protect users' identities.

Though this research does not involve human subjects per se, institutional review board (IRB) approval was nonetheless sought and granted by the Florida State University office of human subjects. Finally, as requested by the IRB, the author personally reached out to the founder and owner of the Wrong Planet website, Alex Plank, and he granted permission to use data from the site with the requirement that it is attributed to Wrong Planet.

\section{Findings}

Data are presented in the manner in which they were created, which is to say that passages are unedited. This is an attempt to provide students with ASD the opportunity to use their own voices, in accordance with the social model of disability studies. In the cases in which the raw data are hard to understand, brackets [] are used to provide clarification. Grammar and spelling mistakes in the raw data remain untouched, and presented as is.

\section{Physical Library Environment}

The physical environment of a library encompasses many aspects. That is, it is not just in reference to the library building itself. This section considers, also, how materials are arranged, why students choose to physically go to the library, what they do while they are there, and the sensory experience that students with ASD encounter while in the library building itself.

\section{Sensory Environment}

In discussions about the library, many Wrong Planet members described both sensory inhibitors and positive sensory experiences. In particular, they described sound or noise and, often, how they do or do not navigate around the explicit and implicit social norms that go along with noise. Some stated they had a very noisy library environment, while others described the quiet library that they used. The data show that Wrong Planet 
members who visit the academic library often either think it is too loud and distracting or they do not know how to adapt to social norms in an environment that is too quiet.

One student in particular started two different discussion threads about being particularly uncomfortable with noises from other people around her in the library. As she states:

I seriously swear I am about to lose my nutts at the rude indian and asian people at the university library who keep sniffing!! I have already asked them nicely to go and blow their noses, and they just wont... argh... I cant conserntrate $n$ this assignments due today... i feel like going to the bathrooms $n$ grabbing a whole pile of hand towls and plonking them on the desk for everyone!! ! earphones $n$ music arent helping either.

There seems to be a frequently held belief that the library is supposed to be quiet, as reinforced by one student who wears headphones to mute the background noise at the academic library "even though in a library, everyone is supposed to remain quiet." This topic emerges throughout the discussion posts, and students with ASD who expect a quiet library seem frustrated when there is, in fact, noise. They describe the noise in different levels, from the aforementioned student who cannot bear the sound of sniffling or humming, to those who claim the entire library is a noisy chaos.

Other students describe the library quite oppositely, as being too quiet. Though often described in a positive way, some students have trouble adapting to the quiet environment. One student says: "Yeh, if you drop a pencil at the University library, all the students glare at you like 'really dude, wtf?'" This sense of nonconformity in the particularly quiet environment is echoed by another student, who describes the following conflict: "I have a really loud voice and the more excited I get the louder it gets. I'm not aware of it until I get shushed, I've been kicked out of the college library loads of times." The fact that he is unaware of the loudness of his voice indicates that he is not adjusting to the social norms of the library's volume until being made aware of it in a rather negative way - perhaps leading to a negative connotation of the library.

\section{Study Rooms and Private Carrels}

Many students describe the positive sensory experiences in study carrels or private study rooms, which tend to be quiet and distraction free. Students often describe study carrels or private rooms when giving advice to other students who are having challenges in finding a quiet place to study. One student gives the following suggestion about finding a study spot on campus: "My best suggestion would be a study cubicle at the library. University libraries often have sound-proofed rooms for group work. You could reserve one for yourself and have utter quiet."

However, many students discuss how it is not enough to simply find a quiet space in the library. Instead, it seems that the physical boundaries of a study room are necessary for a positive experience, to completely remove distractions. As one student said: "And all these 'quiet, private corners' are not too private either; I think I always need at least a cubicle. Also add some anxiety of being watched." Even if the student found a private corner in a common room, he or she felt like someone was watching. Without the privacy of a "cubicle," this awareness of other people sharing the same space serves as a constant distraction for this student.

\section{Library as Place}

One major theme to emerge through open coding is the library as place. Captured within this theme are students who physically go to the library for academic purposes, such 
as studying, or students who simply use the library as an escape. Less often, students described going to the library just to hang out, and this was reflected not in specific mentions, but instead in broad statements such as: "the library is my second home," followed by the response "who needs a home I have the library."

Perhaps one of the most commonly mentioned uses of the library as place is in referring to it as an escape. The students on Wrong Planet use words like "hide out" and "get away." Library as escape is often mentioned in advice that one user will give to another, typically in offering suggestions as to how to get away from a roommate or other unpleasant living situation. The theme of escape also relates to the theme of sensory experiences and, in particular, noise. Many students describe how their living situations are too loud or distracting in general-sometimes in reference to studying or getting academic work done, but often just in reference to noisiness in general.

One member provides this advice to a college student with ASD: "Look around the campus and find a comfortable place to escape from stress and wild kids. When I went I stayed in the library most of the time." Another Wrong Planet member offers similar advice to a college student with ASD who is worried about living with roommates: "You need to secure some solitary hangout spots in and around campus. A hidden nook of the library, a café off-campus that's open late, etc.. Make it so you don't need to come back until your roomie(s) are asleep."

\section{Interactions with Library Resources}

Though many Wrong Planet members describe going to the library for its physical environment, many others simply appreciate accessing library resources. The findings reveal discussions about special interests, advice on both online and in-house resources, checking out materials, and browsing the stacks.

\section{Special Interests}

Some students in this study described focusing narrowly on their own interests and using library materials to research the interests extensively. Though not describing his own interest, one student mentions how the library is useful for this type of research: "the library is good - there is a book there on anything and besides being useful for uni work its good for indulging special interests." A former college student echoes this idea, stating: "I used the university library mostly for exploring my esoteric interests."

\section{Browsing, Serendipity, and Exploration of New Interests}

Some students describe a less intentional experience with materials. These students describe using the library as a place to explore or discover new interests from a broad array of resources.

One example is a Wrong Planet member who describes casually browsing shelves for materials while spending leisure time at the library: "Between classes I spend virtually all my time in the library. I know several very quiet spots and I will walk down the aisles until I find a few interesting books and just go to one of my favorite corners and immerse myself in reading." This sentiment is reinforced by another Wrong Planet member, who states: "The library is an awesome place; I like just being able to read about random things once in awhile."

\section{Resources as a Distraction}

An interesting finding came from those who went to the library to study or complete academic work, yet found themselves distracted by the resources available to them. As one Wrong Planet member describes, in his typical day as a college student: 
Apart from lectures and tutorials, my days tended to consist of being in the library, alone, struggling to find the motivation to study while my head was buried in books that were of interest to me but irrelevant to my actual course...

Being surrounded by books of interest seems to be a distraction for another Wrong Planet member as well: "Sometimes I still get distracted by all the books. I have a few subjects I'm really interested in and I have a hard time not reading about them on my laptop or even reading the books in the library."

\section{Online Materials}

When accessing online resources, it typically seems that the students from this study are looking for sensitive material and they have a specific topic in mind for which they seek information. Additionally, Wrong Planet members are quick to give advice to other students about their online searches and what they found, as well as tips to use their own library databases.

Interestingly, the Wrong Planet members who describe accessing online library resources more often than not discuss health information seeking. In one example, in an extensive discussion about ASD and transgenderism, one student gives information to his or her peers and qualifies it as such:

anyhow found this on my uni library website. dunno if you've tried searching on databases and stuff or if your educational institution (if you are still in education) has stuff like that. try your library. i think i've seen stuff to this effect in mine.

\section{Physical Materials}

Wrong Planet members also often suggest a visit to the library for library books. One student tells another that he could access more information about Asperger's syndrome (AS) from the library: "You could probably get some books at the library about AS. If your library doesn't have the book, then they might be able to borrow it from another library."

Though many students with ASD describe going to the library and spending time there, others are simply interested in getting the resources they need and not spending additional time at the library. As one student states:

I'll go to the library for books I need, but I can't work in there, mostly out of paranoia that other students will look at my work and be judgmental about it. Also, most of the people at my school aren't really there for the education, if you know what I'm saying.

\section{Social and Communicative Experiences}

As individuals with ASD face challenges in communication and social interaction, it is important to know if their experiences in the library help to support these types of interactions, or whether there is more work to be done to facilitate these students' needs. This section describes how students on Wrong Planet discuss communication and social interaction in the library, specifically in regard to the major themes that emerged: knowledge of libraries and materials to support interaction; engagement with others within the library building; and interaction with librarians.

\section{Familiarity and Knowledge to Support Interaction}

Wrong Planet members describe their interactions in using library materials collaboratively, and even for flirting and attracting the attention of potential dates. One user first 
started communicating with another student that he was attracted to by helping her locate a library resource: "She asked me during the first week of school where a book in the library could be found. We began to chat a little more after that..." Familiarity with library resources allowed this individual to share his knowledge in a positive social exchange.

In another case, a student described how he used a library book to improve social interaction with members of the opposite sex: "I found research on dating (books at library) helped me to develop a lie system and playbook to at least emulate someone with a basic level of social skills."

\section{Interaction in the Library Building}

Opportunities for communication and the opportunity for socialization do occur in the library building itself, though these interactions are not always well received. Wrong Planet members described situations of both positive and negative interactions.

First, to address the positive interactions, one student described how he used his special interest to engage socially with a group of other students in the library, among other places:

I'm 22 years old and I sometimes play pokemon in the halls and library of my community college. I often get other adults wanting to hook up Nintendo DS's and play together or just talk about pokemon.

\section{Advice about Interaction}

Wrong Planet members often give one another advice about social interaction when going to the library for academic purposes, such as in forming study groups. One student says:

Get acquainted with the other students in your classes. Form a study group with your student classmates and meet somewhere (the school library, a classroom not being used by another class, a study lounge on campus or some other place) to help each other learn the course material and do well on exams...

Another student offers advice to a fellow Wrong Planet member that he might try to approach potential dates at the library. This advice is met with confusion. "I might try that, but the impression I got was that it was rude to interrupt people in the library."

\section{Avoidance of Interaction}

Many of the conversations describe avoidance of social interaction and communication by spending time at the library. Again, one might refer back to the discussion of "escape" as a theme. Many students describe going to the library specifically to avoid these interactions.

One student enjoys studying at the library, just not having to engage with the people there. She states:

I am alright with being in a library, I can concentrate with noises around me. The only thing that bothers me is people around me everywhere looking at me or interacting with me. I hate it.

Again, the topic comes up that the library is not seen as a place for socializing for one student who goes there to study: "And various people sneaking behind, trying to be friendly. Libraries, as with every public place, unfortunately turns into socializing 
opportunity for some." This is a pretty clear indication that this is not a student who welcomes opportunities for communication and social engagement in the library.

\section{Interaction with Librarians}

Throughout the discussions about academic libraries, there is not much discussion about interactive experiences with librarians. Instead, the librarian appears in these conversations as a hypothetical figure, or described as a group. For example, when one student describes going to the academic library, she first describes the librarians as a whole and then mentions a previous experience as a child in comparison:

I don't like it though, the librarians are really strict. You have to whisper so quiet that you are literally touching the other person's ear with your lips, otherwise, you will get shushed. I get worried that I am going to talk too loud in there and I talk louder when I am nervous. Also, I had a really mean school librarian when I was in grade 1, so I didn't like going back [then] either.

\section{Discussion}

We know that college students with ASD use the library as an escape and as a safe space away from sensory distractions. However, the library itself presents its own set of concerns, largely with either too great or too little noise. There is no clear consensus as to whether a library needs to have absolute quiet or room for collaboration; instead, it seems that Wrong Planet members need a library with designated spaces for each.

Students with ASD do not simply use the library as an escape; they also visit the library to browse materials based on special interests as well as through serendipity. These uses of library resources often occur based on where a student has chosen to situate him- or herself within the library.

Finally, there is a clear lack of engagement from Wrong Planet members with peers and library staff or librarians within the academic library. However, this is often not for lack of desire for social interaction. While some students with ASD clearly state their wishes to be left alone, others seem to have grand ideas of friendships and even romantic relationships initiating within the library environment.

\section{Implications for Practice in Academic Libraries}

There is no single approach in which libraries can support members of this population. This is, of course, an anticipated result that aligns with the current body of knowledge, as all members of this population manifest the characteristics of ASD in individual ways. However, some themes emerged from which academic libraries can adapt services and processes to better suit these students' needs.

\section{Addressing Auditory Concerns}

Students wish to escape to a quiet, sensory-friendly environment, and the data reveal that some see the library as exceptionally loud and chaotic. To address this concern, libraries should provide very obvious signage alerting students to which sections are quiet and in which sections socialization and communication are allowed. Libraries also need to have handouts prepared, available both in the library itself as well as online, alerting students to where they can find both quiet and also more collaborative spaces. These handouts will help students with ASD prepare for their visit to the library well in advance, thus allowing them to feel more comfortable in their experiences.

By specifically stating rules and policies according to library area, students with ASD will better understand what behavior is expected of them where. Adherence to rules or policies is considered by some to be a strong point of many students with 
$\mathrm{ASD}^{44}$ and providing explicit instructions will help them better understand how to best use the library.

\section{Addressing Communication and Social Interaction}

Wrong Planet members describe the difference between their using the library alone and other students who are able to form relationships and make friends. Perhaps it does not have to be such a strong dichotomy. Librarians could provide opportunities for those who are hesitant to socialize, or who typically spend time in the library by themselves, to participate informally in groups. These could be organized by special interests, as we know from the data that many college students use their libraries to explore these interests. While we know that every student will be interested in different things, perhaps groups could be organized to suit a broad array of interests.

\section{Education for Neurotypical Students}

Libraries have the unique opportunity to plan programs and events for the campus community and should use this opportunity to further the campus understanding of students with ASD. This is of utmost importance, as neurotypical students are more accepting of students' idiosyncrasies when they are aware that the individual has a potential ASD diagnosis. ${ }^{45}$ Librarians should invite panelists to present free presentations about the unique needs of students with ASD and how other students can be aware of and supportive of their college experiences. Librarians have a responsibility to provide educational opportunities for students, and this is an important topic that deserves considerable attention.

\section{Training Opportunities for Librarians}

Awareness is the first step toward tailoring the environment, providing access to resources, and creating opportunities for social interaction. As is evident within the literature, the more a campus community is knowledgeable about ASD, the more likely they are in helping students with ASD succeed. ${ }^{46}$ There is no one suggestion in how librarians can best serve their students with ASD, but understanding members of this population and their challenges, as well as the areas in which they excel, will lead to a better library experience both for the students themselves and the librarians who serve them in the academic library. Training opportunities are desired by librarians, and training materials are currently available in various formats, including asynchronous online modules specifically designed for busy librarians. ${ }^{47}$

\section{Conclusion}

This study was an initial exploration into the experiences of college students with ASD and academic library experiences. Continued study of young adults with ASD as presented in their own words, as guided by the social model of disability studies, is necessary and it is clear that there is much more to be learned within this realm. At the time of this writing, further research is being conducted to expand work in the area, including conducting interviews and administering surveys with academic librarians and college students with ASD, to build on the findings of this study and better understand needs and provide services for both populations. ${ }^{48}$

\section{Notes}

1. Diane Adreon and Jennifer Durocher, "Evaluating the College Transition Needs of Individuals with High-Functioning Autism Spectrum Disorders," Intervention in School and Clinic 42, no. 5 (May 2007): 271-79; Gena P. Barnhill, "Supporting Students with Asperger Syndrome 
on College Campuses Current Practices," Focus on Autism and Other Developmental Disabilities 31, no. 1 (Mar. 10, 2014), 3-15; Nicholas W. Gelbar, Isaac Smith, and Brian Reichow, "Systematic Review of Articles Describing Experience and Supports of Individuals with Autism Enrolled in College and University Programs," Journal of Autism and Developmental Disorders 44, no. 10 (2004): 2593-2601; Stephanie Pinder-Amaker, "Identifying the Unmet Needs of College Students on the Autism Spectrum," Harvard Review of Psychiatry 22, no. 2 (Mar./Apr. 2014): 125-37.

2. American Psychiatric Association, Autism Spectrum Disorder, last modified 2013, available online at www.wpic.pitt.edu/research/CeFAR/PDF/dsm-5-autism-spectrum-disorder-fact-sheet[1] . pdf [accessed 8 March 2017].

3. Emily Lawrence, "Loud Hands in the Library: Neurodiversity in LIS Theory and practice," Progressive Librarian 41 (2013): 98-109.

4. Lawrence, "Loud Hands in the Library," 103.

5. "Garry," in Aquamarine Blue: Five Personal Stories of College Students with Autism, ed. Dawn Prince-Hughes (Athens, Ohio: Swallow Press/Ohio University Press, 2002), 1-8; Temple Grandin, "A Personal Perspective of Autism," in Handbook of Autism and Pervasive Developmental Disorders, vol. 2, 3rd ed., eds. Fred R. Volkmar et al. (Hoboken, N.J.: John Wiley \& Sons, 2005), 1276-86; Holly Halvorson, "Asperger's Syndrome: How the Public Library Can Address These Special Needs," Children E Libraries: The Journal of the Association for Library 4, no. 3 (Winter 2006): 19-27; Maurini Strub and Louann Stewart, "Case Study: Shelving and the Autistic Employee," Journal of Access Services 7, no. 4 (Oct. 2010): 262-68.

6. "Garry," 3.

7. Barnhill, "Supporting Students with Asperger Syndrome on College Campuses," 3-15.

8. American Psychiatric Association, Autism Spectrum Disorder.

9. American Psychiatric Association, Autism Spectrum Disorder; Janice E. Janzen and Catherine B. Zenko, Understanding the Nature of Autism: A Guide to the Autism Spectrum Disorders, 2nd ed. (Austin, Tex.: Hammill Institute on Disabilities, 2002); Charlie Remy and Priscilla Seaman, "Evolving from Disability to Diversity: How to Better Serve High-Functioning Autistic Students," Reference $\mathcal{E}$ User Services Quarterly 54, no. 1 (n.d.): 24-28; Dianne Zager et al., Educating College Students with Autism Spectrum Disorders (New York, N.Y.: Routledge, 2012).

10. Remy and Seaman, "Evolving from Disability to Diversity"; Zager et al., Educating College Students with Autism Spectrum Disorders.

11. Adreon and Durocher, "Evaluating the College Transition Needs of Individuals with High-Functioning Autism Spectrum Disorders," 271-79; Barnhill, "Supporting Students with Asperger Syndrome on College Campuses," 3-15; Gelbar, Smith, and Reichow, "Systematic Review of Articles Describing Experience and Supports of Individuals with Autism Enrolled in College and University Programs," 2593-2601; Pinder-Amaker, "Identifying the Unmet Needs of College Students on the Autism Spectrum," 125-37.

12. Remy and Seaman, "Evolving from Disability to Diversity," 24-28; Paul Wyss, "Asperger's in Academia: A Personal Narrative of Failure and Success from a Librarian with Asperger's Syndrome," in Proceedings of World Conference on E-Learning in Corporate, Government, Healthcare, and Higher Education 2014, ed. Theo Bastiaens (Chesapeake, Va.: Association for the Advancement of Computing in Education AACE, 2014), 2109-14; Zager et al., Educating College Students with Autism Spectrum Disorders.

13. Gelbar, Smith, and Reichow, "Systematic Review of Articles Describing Experience and Supports of Individuals with Autism Enrolled in College and University Programs," 2593-2601.

14. Barnhill, "Supporting Students with Asperger Syndrome on College Campuses," 3-15.

15. Ibid.

16. Jim Sinclair, “Why I Dislike 'Person First' Language," Autonomy, the Critical Journal of Interdisciplinary Autism Studies 1, no. 2 (Oct. 2013).

17. Valérie Van Hees, Tinneke Moyson and Herbert Roeyers, "Higher Education Experiences of Students with Autism Spectrum Disorder: Challenges, Benefits and Support Needs," Journal of Autism and Developmental Disorders 45, no. 16 (June 2015): 1673-88.

18. Remy and Seaman, "Evolving from Disability to Diversity," 24-28.

19. Susan W. White, Thomas H. Ollendick, and Bethany C. Bray, "College Students on the Autism Spectrum: Prevalence and Associated Problems," Autism 15, no. 6 (May 2011): 683-701.

20. Christine Breakey, The Autism Spectrum and Further Education: A Guide to Good Practice (London: Jessica Kingsley Publishers, 2006); Nick Chown and Nick Beavan, "Intellectually Capable but Socially Excluded? A Review of the Literature and Research on Students with Autism in Further Education," Journal of Further and Higher Education 36, no. 4 (2012): 477-93; Julie Q. Morrison, Frank J. Sansosti, and Wanda M. Hadley, "Parent Perceptions of the Anticipated Needs and Expectations for Support for Their College-Bound Students with Asperger's Syndrome," Journal of Postsecondary Education and Disability 22, no. 2 (2009): 78-87; Remy and Seaman, "Evolving from Disability to Diversity," 24-28; Leigh Ann Tipton and Jan Blacher, "Brief Report: Autism 
Awareness: Views from a Campus Community," Journal of Autism and Developmental Disorders 44, no. 2 (Feb. 2014): 477-83; Sasha M. Zeedyk, Leigh Ann Tipton, and Jan Blacher, "Educational Supports for High Functioning Youth with ASD: The Postsecondary Pathway to College," Focus on Autism and Other Developmental Disabilities 31, no. 1 (Mar. 2014): 37-48.

21. Tipton and Blacher, "Brief Report: Autism Awareness: Views from a Campus Community," $477-83$.

22. Lawrence, "Loud Hands in the Library," 105.

23. Gelbar, Smith, and Reichow, "Systematic Review of Articles Describing Experience and Supports of Individuals with Autism Enrolled in College and University Programs," 2593-2601; Ken Gobbo and Solvegi Shmulsky, "Faculty Experience with College Students with Autism Spectrum Disorders: A Qualitative Study of Challenges and Solutions," Focus on Autism and Other Developmental Disabilities 29, no. 1 (Oct. 2013): 13-22; Morrison, Sansosti, and Hadley, "Parent Perceptions of the Anticipated Needs and Expectations for Support for Their College-Bound Students with Asperger's Syndrome," 78-87; Van Hees, Moyson and Roeyers, "Higher Education Experiences of Students with Autism Spectrum Disorder," 1673-88.

24. Aquamarine Blue 5: Personal Stories of College Students with Autism, ed. Dawn Prince-Hughes (Athens, Ohio: Swallow Press/Ohio University Press, 2002).

25. Janzen and Zenko, Understanding the Nature of Autism; Remy and Seaman, "Evolving from Disability to Diversity," 24-28.

26. "Garry," 1-8; Grandin, "A Personal Perspective of Autism," 1276-86; Halvorson, "Asperger's Syndrome: How the Public Library Can Address These Special Needs," 19-27; Strub and Stewart, "Case Study: Shelving and the Autistic Employee," 262-68.

27. Andrea Bress, "Making Your School Library More Functional to Individuals with Autism," Library Media Connection 32, no. 1 (Aug. 2013): 46-47.

28. Theresa L. Schlabach, “The College Experience of Students with Asperger's Disorder: Perceptions of the Students Themselves and of College Disability Service Providers Who Work with These Students" (dissertation, Illinois State University, 2008).

29. Abigail Delehanty et al., "Supporting Social Communication Opportunities for Students with ASD through Professional Development: Project PALS," lecture presented at the American Speech-Language-Hearing Association Annual Conference, Denver, Colo., 2015; Remy and Seaman, "Evolving from Disability to Diversity," 24-28.

30. Harvey Molloy and Latika Vasil, "The Social Construction of Asperger Syndrome: The Pathologising of Difference?" Disability \& Society 17, no. 6 (2002): 668.

31. Ibid., 668.

32. "Concern over the Use of the Social Model of Disability, in the Autism Community," Autism \& Oughtisms (2011), available online at https://autismandoughtisms.wordpress.com/2011/12/16/ concern-over-the-use-of-the-social-model-of-disability-in-the-autism-community/ [accessed 5 March 2017].

33. Kenny Lorcan, Caroline Hattersley, Bonnie Molins, Carole Buckley, Carol Povey, and Elizabeth Pellicano, "Which Terms Should Be Used to Describe Autism? Perspectives from the UK Autism Community," Autism 20, no. 4 (2016): 442-62; Sinclair, "Why I Dislike 'Person First' Language."

34. David Silverman, Doing Qualitative Research: A Practical Handbook (Thousand Oaks, Calif.: SAGE Publications Limited, 2000), 28.

35. Ulrike Pfeil and Panayiotis Zaphiris, "Applying Qualitative Content Analysis to Study Online Support Communities," Universal Access in the Information Society 9, no. 1 (2010): 1-16.

36. Charlotte Brownlow and Lindsay O'Dell, “Constructing an Autistic Identity: AS Voices Online," Mental Retardation 44, no. 5 (Oct. 2006): 315-21.

37. Charlotte Brownlow, Lindsay O'Dell, and Hanna Bertilsdotter Rosqvist, “Commentary: Challenging Representations of Autism-Exploring Possibilities for Broadcasting the Self on YouTube." Journal on Developmental Disabilities 19, no. 1 (2013): 90-95; Brownlow and O'Dell, "Constructing an Autistic Identity," 315-21.

38. Juanne Clarke and Gudrun van Amerom, "'Surplus Suffering': Differences between Organizational Understandings of Asperger's Syndrome and Those People Who Claim the 'Disorder,'” Disability \& Society 22, no. 7 (2007): 761-76; Kristen Faye Linton et al., "Opinions of People Who Self-identify with Autism and Asperger's on DSM-5 Criteria," Research on Social Work Practice 24, no. 1 (July 2013): 67-77; Chloe J. Jordan and Catherine Caldwell-Harris, "Understanding Differences in Neurotypical and Autism Spectrum Special Interests Through Internet Forums," Intellectual and Developmental Disabilities 50, no. 5 (Oct. 2012):391-402; Chloe J. Jordan, "Evolution of Autism Support and Understanding Via the World Wide Web," Intellectual and Developmental Disabilities 48, no. 3 (June 2010): 220-27; David C. Giles, “'DSM-V Is Taking Away Our Identity': The Reaction of the Online Community to the Proposed Changes in the Diagnosis of Asperger's Disorder," Health: An Interdisciplinary Journal for the Social Study of Health, Illness and Medicine 18, 
no. 2 (June 2013): 179-95; Brownlow and O'Dell, “Constructing an Autistic Identity,” 315-21.

39. Jordan and Caldwell-Harris, "Understanding Differences in Neurotypical and Autism Spectrum Special Interests Through Internet Forums," 391-402.

40. Jordan, "Evolution of Autism Support and Understanding Via the World Wide Web," 220-27.

41. Pfeil and Zaphiris, "Applying Qualitative Content Analysis to Study Online Support Communities," 9.

42. Michael Quinn Patton, Qualitative Research E Evaluation Methods: Integrating Theory and Practice, 4th ed. (Thousand Oaks, Calif: SAGE Publications, 2015).

43. Clarke and van Amerom, "Surplus Suffering."

44. Zager et al., Educating College Students with Autism Spectrum Disorders.

45. Nicole L. Matthews, Agnes R. Ly, and Wendy A. Goldberg, “College Students' Perceptions of Peers with Autism Spectrum Disorder," Journal of Autism and Developmental Disorders 45, no. 1 (Jan. 2015): 90-99; Robert Butler and Jennifer M. Gillis, "The Impact of Labels and Behaviors on the Stigmatization of Adults with Asperger's Disorder," Journal of Autism and Developmental Disorders 41, no. 6 (June 2011): 741-49.

46. Tipton and Blacher, "Brief Report: Autism Awareness: Views from a Campus Community," 477-83.

47. Delehanty et al., "Supporting Social Communication Opportunities for Students with ASD through Professional Development: Project PALS."

48. Kate Mullen, "FSU Researchers Win Grant to Better Serve Library Patrons on the Autism Spectrum," Florida State University News, available online at http://news.fsu.edu/news/educationsociety/2016/09/27/fsu-researchers-win-grant-better-serve-library-patrons-autism-spectrum/ [accessed 13 July 2017]. 